during conditioning with the exception that the CS was omitted. Hall of the se Sis received their 10 shocks in the cylindrical chamber and the other half in the operant box.

Suppression testing involved return of all Ss to the operant box for continuous food reinforcement, and three $30-\mathrm{sec}$ CS presentations at randomly selected intervals.

\section{RESULTS}

Suppression ratios (SR) were formed by dividing the number of responses during CS presentations (B) by the sum of the responses during the $30-\mathrm{sec}$ period prior to the CS onset $(A)$ and those during $B$ [i.e., $\mathrm{SR}=\mathrm{B} /(\mathbf{A}+\mathbf{B})]$

Since a nested-factors design was employed, several analyses were required to fully evaluated the data. Figure 1 summarizes part of the test results. As seen, the US control group exhibited suppression to the CS on the first, but fully recovered by the third test trial. There was no difference between the performances of this and the two FC (forward conditioned) groups who had received PCS exposures in the operant chamber $(1<1)$. However, the two FC groups who did not get PCS exposures in the operant box exhibited consistently greater test suppression than the other three.

Analyzing the data of all four FC groups, the only significant $F$ was for PCS conditions $(F=14.65$, df $=1 / 20, p<.01)$ thus supporting the observation of relatively greater suppression for the two forward conditioned groups who did not receive PCS exposures in the operant box. Separate comparisons indicated that the PCS (in the operant box) and US control groups differed from the non-PCS, forward conditioned groups (all ps $<.025$ ). (It should be noted that SRs for the respective halves of the US controls were undistinguishable.)

Since the presence or absence of PCS exposures in the holding cages was a nested factor, a separate analysis of these data was conducted. Again, the only reliable effect for this analysis resulted from the greater suppression for the groups who did not receive PCS exposures (overall mean median $\mathrm{SR}=.07$ ) as opposed to those who did (overall mean median $\mathrm{SR}=.19$ ) in the holding cages $(\mathrm{F}=7.30, \mathrm{df}=1 / 10$, $\mathrm{p}<.025$ ).

A comparison of the intermediately suppressed performance of the FC group who received PCS exposures in the holding cages (combined from the Ss conditioned in the box and in the coil) with those of the FC groups who had been given PCS exposures in the operant box indicated reliably less test suppression for the latter ( $F=5.88$, $\mathrm{df}=1 / 15, \mathrm{p}<.05)$.

\section{DISCUSSION}

Place of conditioning does not seem important relative to the location of PCS exposures. Even though the coil and the operant box were highly physically differ- ent, the effect of conditioning in either was identical whe ther PCS exposures occurred in the operant environment or in the holding cage. However, place of PCS exposure appears important. Groups who received preexposures in the test situation exhibited no suppression to test presentations of the CS while comparably conditioned groups who received PCS exposures (identical physical intensity) elsewhere exhibited pronounced suppression. However, PCS exposures still offset conditioning when they occurred outside the test environment. These latter Ss exhibited less suppression that those who did not receive the PCS treatment anywhere.

At least three somewhat different theoretical notions have been suggested to account for the effect of PCS exposures. Carlton \& Vogel (1967) have proffered a habituation notion, but did not offer an account for how a habituated stimulus fails to become conditioned. This interpretation also may encounter a logical difficulty. Thompson \& Spencer (1966) have indicated that a habituated response invariably can be dishabituated by a strong stimulus. Although Thompson \& Spencer (1966) have argued cogently that dishabituation may be a separate process from habituation, their development nevertheless would suggest abrupt dishabituation to the strong shocks used for conditioning.

A second hypothesis is that some sort of contextual discrimination between place of PCS exposure and conditioning may occur, the result being that $S$ may learn that the CS is not a signal for shock in one environment but is in another (cf. Anderson et al, 1968). This interpretation is not confirmed in the present study since the two groups who received PCS exposures in the operant box performed identically even though one was conditioned in the same environment.

Interestingly, Lubow (1965) has proposed that PCS exposures may result in acquisition of responses which are incompatible with classical defensive training. It is difficult to see how this notion can account for the differential effectiveness of PCS exposures in different environments while, at the same time, handle the relative insensitivity of the PCS effect to highly different conditioning situations.

\section{REFERENCES}

ANDERSON, D. C., MERRILL, H. K., DEXTER, W. \& ALLEMAN, H. Contextual effects in emotional learning. Proceedings of the American Psychological Association, 1968, 3, 147-148.

ANDERSON, D. C., WOLF, D., \& SULLIVAN, $P$. Preconditioning exposures to the CS: Variations in place of testing. Psychonomic Science, in press.

CARLTON, P. L., \& VOGEL, J. R. Habituation and conditioning. Journal of Comparative \& Physiological Psy chology, 1967, 63, 348-351.

GRANT, D. A., HAKE, H.W, RIOPELLE, A. J. \& DOSTLAN, A. Effects of repeated pretesting with conditioned stimulus upon extinction of the conditioned eyelid response to light. American Joumal of Psychology, 1951, 54, 247-252.

LUBOW, R. E. Latent inhibition: Effects of frequency of nonreinforced preexposure of the CS. Journal of Comparative \& Physiological Psychology, 1965, 60, 454-457.

LUBOW, R. E., \& MOORE, A. U. Latent inhibition: The effect of nonreinforced preexposure to the conditional stimulus. Journal of Comparative \& Phy siological Psychology, 1959, 52,415-419.

THOMPSON, R. F., \& SPENCER, W. A. Habituation: A model phenomenon for the study of neuronal substrates of behavior. Psy chological Review, 1966, 73, 16-43. NOTE

1. This research was supported by Grant $\mathrm{MH}$ 15364-01 from the National Institute of Mental Health, USPHS.

\title{
Behavior of infant rhesus monkeys with thalidomide-induced malformations: A pilot study
}

D. G. LINDBURG ${ }^{2}$ National Center for Primate Biology, University of Califormia, Davis, Calif. 95616

Infant monkeys having gross upper limb malformations compensate for manually performed tasks by using the mouth and feet. In overall levels of maternal, peer, and environmental interaction they showed a slight deficit only in exploratory activity in comparison with normal infants.

In concert with a study of thalidomide. induced teratology in thesus monkeys, two infants with gross upper limb deformities were made available for behavioral studies. These animals were bipedal in their locomotion, and could neither cling to the mother without support nor engage in the manipulative activities characteristic of normal monkeys. In addition to a study of locomotor and manipulative skills, a pilot study was designed to permit assessment of maternal-infant behavior and the development of social interaction with peers. There have been no previous reports on the possible effects of thalidomide on the behavior of any nonhuman primate. 


\section{SUBJECTS}

The test animals were two thalidomidemalformed male infants ( $T$ ), matched with two normal males $(N)$ of the same age. All were born at the National Center for Primate Biology and were individually caged with their mothers throughout the observation period. At 14 weeks of age they were transferred to the behavior section, located in a $13 \times 28 \mathrm{ft}$ section of a Speedspace building.

\section{APPARATUS}

The four Ss were housed in $3 \times 3 \mathrm{ft}$ wire cages at opposite ends of a $3 \times 6 \mathrm{ft}$ play unit of similar construction. Access to the play unit was controlled by a sliding door opened wide enough to permit only the infants to enter.

\section{PROCEDURE}

The Ss were given a 2-week period of adaptation to the test unit. Observations of mother-infant interactions were carried out in the home cages. Starting at 4 months of age and ending at 11 months, each animal was observed for $15 \mathrm{~min}$ on alternate days, 3 days per week. All sessions occurred between $10 \mathrm{AM}$ and 12 noon and sessions were balanced for treatment and order of testing. Scoring sessions were divided into 15 -sec intervals and each of 10 infant and 6 maternal behaviors was scored once for each interval in which it occurred. Scores were summed for seven 12 -session blocks and a terminal 9-session block.

Home cage sessions were followed by 19-min sessions in which infants were paired. In the first and last $2 \mathrm{~min}$ of each session, Ss were scored only for location in the test unit. For the first 12 weeks, each of two pairings was observed for 2 successive days, after which two new pairs were formed; thus, in a 6-day week all six possible pairings had been observed for two successive sessions. Order of testing and intervals were as indicated above. From weeks 13-31, paired sessions for each of the six pairs were reduced to one per week. Sixteen infant and five maternal behaviors were recorded. With slight modification, the behavioral categories used were similar to those employed by Hansen (1966).

\section{RESULTS}

Body contact between mother and infant was higher in $\mathrm{N}$ animals through the sixth month of age. Thereafter, contact levels were nearly identical and declined markedly from a mean of $56 \%$ of intervals at 7 months to a low of $12.5 \%$ at 10 months. The nature of contact differed only in mothers of $T s$ tending to cradle at a higher level throughout most of the study, probably to provide support when sitting with $T$ in the ventral position. When carrying ventrally, $T$ mothers had to provide support due to the inability of Ts to cling with their forelimbs. Nevertheless, in the spatially limited cage environment, there were no appreciable differences in total amount of ventral carrying between $\mathrm{Ts}$ and $\mathrm{Ns}$.

In general, Ns were rejected or punished by mothers at a higher level than $\mathrm{Ts}$ throughout $(\mathrm{N}$ range $=8.13 \%, \mathrm{~T}$ range $=$ $6-9 \%)$, but initially this pattern showed considerable overlap between individual Ss. $T$ levels showed a gradual decline with age, whereas $\mathbf{N}$ levels were more variable from month to month.

All infants groomed their mothers infrequently. One $T$ groomed with its deformed upper limbs, the other with its feet.

Infant interactions in the play sessions consisted primarily of play and exploration of the unit itself. Grooming between infants was not seen, and aggressive and sexual interactions were rare. There were no clear differences in maternal attempts to retrieve infants from the play unit. However, mothers of $T$ infants consistently threatened their offspring's playmates at a higher rate than mothers of $\mathrm{N}$ infants. Threats directed to their own infants were highly variable from week to week, suggesting that the greater protectiveness of $\mathrm{T}$ mothers was a true difference.

During play sessions the $\mathrm{N}$ infants spent more time in exploratory activity (Mean $62.5 \%$ of intervals) than the $\mathrm{T}$ infants (Mean $44.9 \%)$. For the different pairings, the level of exploration from highest to lowest was $\mathrm{N}$ with $\mathrm{N}, \mathrm{N}$ with $\mathrm{T}, \mathrm{T}$ with $\mathrm{N}$, and $\mathrm{T}$ with $\mathrm{T}$. The lower levels for $T$ animals reflected the tendency to follow vigorous bouts of play with short periods of rest, whereas $N$ animals shifted to exploratory activity when not playing.

Suprisingly, one of the T Ss showed the highest overall frequency of rough-andtumble play. The second $T$ infant was virtually indistinguishable from one of the $N$ $\mathrm{Ss}$ in frequency of this activity. Although the levels for each S probably reflected only individual variation, the study does indicate that the malformed animals were not deficient in their capacity for this kind of vigorous social interaction. The same is true for avoidance-withdrawal play, for although pooled data showed that Ns maintained slightly higher levels throughout, one of the Ts was intermediate between the two Ns in this activity. This was probably a strenuous activity for the bipeds, since it consisted of chasing or fleeing from one end of the play unit to the other. As noted above, Ts often took short rest pauses after these bouts.

There was little difference in nonsocial play after the seventh month of age, although levels of nonsocial play for both $T$ and $\mathrm{N}$ animals were highest when paired with another $\mathrm{T}$. For all kinds of play activity combined, the frequencies probably showed only individual propensities for the four Ss.
Pooled data showed the Ns played at levels $2-7 \%$ higher than Ts, with the exception of one 4-week block ( 11 months of age) when the $\mathrm{T}$ level was $3 \%$ higher than the $\mathrm{N}$ level. However, each T S resembled an N S more than it resembled another $T$.

DISCUSSION

The teratogenic effects of thalidomide on the fetal development of monkeys have been well documented in a number of studies (Delahunt \& Lassen, 1964; Wilson \& Gavan, 1967; Wilson, Fradkin, \& Hardman, 1968), but to date there have been no published reports on the postnatal behavioral development or performance of monkeys subjected to this treatment. The limited conclusions which may be drawn from the present study indicate that rhesus infants with upper limb malformations are not greatly impaired in their ability to achieve adequate levels of maternal, peer, and environmental interaction. The one possible exception is in exploratory activity. This difference is probably an indication of the greater ease with which normal infants could traverse distances, since the bipeds often paused for short rest periods following extensive locomotion while the normals were exploring. Activities carried out by use of the hands in normal animals (grooming, manipulation, object carrying) were performed with the feet or mouth in the malformed Ss. First appearance of specific behaviors and increase or decline of particular patterns over time showed no evidence of a developmental lag between normal and malformed animals.

Apart from support while carrying, a slightly higher incidence of cradling, and a suggestion of overprotectiveness through threatening their infants' playmates, mothers of the malformed infants did not obviously compensate for their offspring's handicap by modifying their own behavior. Most adult female differences suggest only individual propensities for mothering.

\section{REFERENCl:S}

DELAHUNT, C. S., \& LASSEN, L. J. Thalidomide syndrome in monkeys. Science, 1964, 146, 1300-1305.

HANSEN, 1: W. The development of maternal and infant behavior in the rhesus monkey. Behaviour, 1966, 27, 107-149.

WILSON, J.G., FRADKIN, R., \& HARDMAN, A. A. Progress report on teratological testing of drugs in rhesus monkeys. Teratology, 1968, 1, 223.

WILSON, J. G., \& GAVAN, J. A. Congenital malformations in nonhuman primates: spontaneous and experimentally induced. Anatomical Record, 1967, 158, 99-110. NOTES

1. This research was supported by National Institutes of llealth Grant F.R00169 to the National Center for Primate Biology, Davis, California.

2. I thank Dr. (. Mit thell for critical reading of the manuscript. and Mrs. Patricia Abranss for assisting in datia andysis. 